\title{
MODEL SISTEM BERBASIS PENGETAHUAN UNTUK REKOMENDASI
} AKTIVITAS PENSIUN

\author{
Dono Catur Prasetyo ${ }^{* 1}$, Sri Kusumadewi ${ }^{2}$, Isnatin Miladiyah ${ }^{3}$ \\ ${ }^{1,2,3}$ Universitas Islam IndonesiaYogyakarta \\ Email: ${ }^{1} 16917207 @$ students.uii.ac.id, ${ }^{2}$ sri.kusumadewi@uii.ac.id, ${ }^{3}$ isnatin@uii.ac.id \\ *Penulis Korespondensi
}

(Naskah masuk: 10 Desember 2020, diterima untuk diterbitkan: 18 Oktober 2021)

\begin{abstract}
Abstrak
Masa Pensiun merupakan bagian dari fase kehidupan setiap orang. Ketika seseorang memasuki fase pensiun akan banyak perubahan yang terjadi di dalam proses kehidupannya, beberapa tanda perubahan kehidupan yang dapat ditemukan yaitu kehilangan finansial, kehilangan status, kehilangan teman/kenalan dan berakhirnya rutinitas kerja. Sebagian besar orang belum mempersiapkan masa pensiun dengan baik, pensiun diasumsikan sebagai pemutus rutinitas yang sudah dijalani selama masa produktifnya. Penelitian ini bertujuan untuk membangun model sistem berbasis pengetahuan untuk memberikan rekomendasi aktivitas dalam menghadapi masa pensiun. Dalam menentukan aturan basis pengetahuan pada penelitian ini menggunakan beberapa faktor yaitu: psikis, medis, ekonomi, lingkungan, pendidikan dan jabatan. Adapun batasan umur calon pensiunan yang di gunakan penelitian ini lebih dari atau sama dengan 55 tahun dan pengguna sistem ini nantinya hanya untuk ruang lingkup instansi pemerintahan. Pengetahuan yang ada di dalam sistem berbasis pengetahuan dapat di representasikan dengan beberapa cara. Adapun Representasi pengetahuan sistem menggunakan kaidah produksi, proses inferensi menggunakan forward chaining dan proses perhitungan nilai kepastian menggunakan metode certainty factor. Forward chaining digunakan untuk proses pelacakan dari faktor-faktor yang telah terpilih untuk kemudian mencocokan dengan rule yang sudah ada di sistem agar dapat memberikan suatu konklusi, setelah ditemukan rule yang cocok dari faktor-faktor yang terpilih kemudian di hitung dengan metode certainty factor untuk mengetahui tingkat keyakinan konklusi. Pada penelitian ini terkumpul sebanyak 42 faktor dan 10 rekomendasi. Hasil dari penelitian ini setelah melakukan pengujian User Acceptance Test (UAT) terhadap 30 responden pada sistem menghasilkan kesimpulan bahwa sistem ini membantu dalam memberikan rekomendasi aktivitas untuk persiapan pensiun dengan persentase $87,4 \%$, tampilan antarmuka sistem sangat menarik dan juga informasi yang diberikan sangat jelas dengan persentase $86 \%$, sistem yang dibangun ini mudah digunakan dengan persentase $82,6 \%$ dan sistem yang dibangun ini mudah dipelajari dengan persentase $80,6 \%$. Hal tersebut ditunjukkan dengan nilai rata-rata persentase sebesar 80,06 \% akan tetapi pada hasil konsultasi yang diberikan sistem sesuai dengan yang diharapkan memberikan persentase sebesar 67,2\% karena pada keterangan rekomendasi yang diberikan belum ditampilkan dengan lengkap. Dan dari pengujian blackbox memberikan hasil fungsi-fungsi pada sistem yang dibangun dapat berjalan dengan baik.
\end{abstract}

Kata kunci: masa pensiun, forward chaining, certainty factor, basis pengetahuan

\section{KNOWLEDGE-BASED SYSTEMS MODEL FOR RECOMMENDATIONS TO RETIREMENT ACTIVITIES}

\begin{abstract}
Retirement is part of everyone's life phase. When a person enters the retirement phase, there will be many changes that occur in the process of their life, some signs of life change that can be found are financial loss, loss of status, loss of friends or acquaintances and the end of the work routines. Most people haven't prepared well for retirement, retirement is assumed to be a breaker of the routine that has been undertaken during their productive period. This study aims to build a knowledge-based system model to provide recommendations for activities in phase of retirement. In determining the rules of the knowledge base in this study, several factors are used, that is: psychological, medical economic, environmental, educational, and occupational. As for the age limit of prospective retirees used in this study in more than or equal to 55 years and the users of this system will only be for the scope of government. The knowledge contained in a knowledge-based system can be represented in several ways. As for the representation of system knowledge using production principles, the inference process uses forward chaining and the process of calculating the certainty value uses certainty factor method. Forward chaining is used for the tracking process of the factors that have been selected to match the rules that
\end{abstract}


already exist in the system, in order to provide a conclusion, after finding a suitable rule from selected factors, then calculated with certainty factor method to find out level of conclusive confidence. In this study, many 42 factors and 10 recommendations were collected. The results of this study after testing user acceptance test (UAT) of 30 respondents in the system resulted in the conclusion that this system helps provide recommendations for activities for retirement preparation with a percentage of $87,4 \%$, the system interface is very interesting and the information provided is very clear with a percentage of $86 \%$, the system built is easy to use with a percentage of $82,6 \%$ and the system built is easy to learn with a percentage of $80,6 \%$. This is indicated by an average percentage value of $80,06 \%$, but the results of the consultation provided by the system are as expected, giving a percentage of $67,2 \%$ because the information provided hasn't provided detailed information only in general. From blackbox examination, the functions of the system that are built can run properly.

Keywords: retirement, forward chaining, certainty factor, knowledge base.

\section{PENDAHULUAN}

Pensiun adalah fase krusial dalam dunia karier seseorang, masa pensiun merupakan fase transisi kehidupan baru dari rutinitas dunia kerja yang secara alamiah pasti akan dihadapi setiap orang (Paidi, 2013). Ketika seseorang memasuki fase pensiun akan terjadi perubahan tatanan didalam kehidupannya, beberapa perubahan tersebut yaitu kehilangan finansial, kehilangan status, kehilangan teman atau kenalan dan berakhirnya rutinitas kerja (Darmojo \& Martono, 2015). Secara psikologis mekanisme koping setiap individu berbeda dalam menghadapi masa pensiun (purnabakti). Beberapa individu berspektif masa pensiun merupakan momen yang sudah lama dinantikan untuk menikmati hari tua dengan bahagia, tetapi di sisi lain ada yang mengalami kecemasan terhadap masa pensiun yang akan di jalani di usia lanjutnya karena memasuki usia tua dengan kondisi fisik semakin lemah, menderita banyak penyakit dan merasa tidak dibutuhkan lagi karena produktivitas yang semakin menurun (Paidi, 2013).

Fase transisi kehidupan pensiun yang dianggap sebagai kenyataan yang tidak menyenangkan di karenakan dari rutinitas kehidupan sebelumnya yang dipenuhi tugas perusahaan/kantor, rapat kerja harian secara berkala kemudian semua rutinitas tersebut tiba-tiba berhenti. Sehingga hadir perasaaan kesepian, yang menyebabkan penurunan rasa percaya diri, kecemasan, stress, kesehatan fisik, kesehatan psikologis seseorang (Safitri, 2013). Beragam fenomena psikologis yang dapat muncul, seperti merasa bingung dengan aktivitas apa yang harus dilakukan jika tidak memiliki kegiatan lagi, merasa dirinya biasa-biasa saja karena kegiatan yang dilakukan hanya tidur, makan, dan berdiam diri dirumah (Kadarisman, 2011).

Oleh karena itu dengan perkembangan teknologi informasi saat ini, maka permasalahan itu dapat diselesaikan dengan pendekatan teknologi informasi. Hal ini terkait dengan peran IT yang sudah masuk kedalam berbagai bidang kehidupan sebagai contoh dalam bidang kedokteran. Salah satu perkembangan teknologi informasi saat ini adalah kecerdasan buatan atau Artificial Intelegence (AI) yang mampu meniru atau mempelajari kecerdasan manusia.
Dalam bidang kecerdasan buatan ini memiliki cakupan yaitu Sistem Pakar (Expert System), Teknologi IT yang dapat meniru Seorang Pakar untuk dapat membantu masyarakat awam. Program kecerdasan buatan komputer yang dirancang memiliki kemampuan untuk menyelesaikan masalah seperti yang dilakukan oleh seorang pakar disebut sebagai Sistem Pakar. Tujuan dirancangnya Sistem Pakar yaitu untuk menyelesaikan permasalahan yang cukup rumit yang hanya bisa diselesaikan oleh para ahli. Certainty factor adalah metode untuk mencari nilai kepastian, yang digunakan untuk mendiagnosa sesuatu yang belum pasti (Rahman, 2017). Certainty factor dijadikan indikator penilaian klinis yang ditetapkan oleh seorang pakar dalam mengidentifikasi tingkat kepercayaan. Sedangkan forward chaining adalah program yang digunakan dalam pelacakan pada sistem pakar. Mekanisme dari Forward Chaining adalah dengan melakukan program pencarian atau pelacakan ke depan yang dimulai dari informasi yang ada serta penggabungan rule sehingga output yang dihasilkan dari program ini yaitu suatu kesimpulan atau tujuan.

Berdasarkan uraian diatas, dapat dikembangkan sistem pakar yang dapat membantu pekerja atau pegawai yang akan memasuki masa pensiun dalam menentukan jenis aktivitas produktif. Dirancangnya sistem pakar ini menjadi referensi dalam memberikan solusi untuk merekomendasikan aktivitas-aktivitas produktif yang dapat dilakukan pada masa pensiun agar dapat meningkatkan kualitas hidup dari pekerja/pegawai.

\section{METODE PENELITIAN}

\subsection{Sistem Pakar}

Sistem pakar adalah sistem berbasis komputer yang menggunakan fakta, nalar, serta pengetahuan manusia, sehingga dapat menyelesaikan masalah sebagaimana yang dilakukan oleh pakar di bidangnya. Sistem pakar memang dapat membantu kehidupan manusia, karena sistem dapat memahami dan meniru mekanisme kecerdasan manusia melalui penggunaan komputer, sehingga memiliki pengetahuan yang serupa dengan pakar (Pratiwi, 2019). 
Konsep dasar sistem pakar berbasis pengetahuan (knowledge based expert system) secara internal, sistem terdiri dari dua komponen utama yaitu basis pengetahuan (knowledge based) yang berisi pengetahuan, dimana pengetahuan ini diambil dari pengetahuan pakar dan mesin inferensi (inference engine) digunakan untuk menghasilkan saran sebagai respon dari user (Rosnelly, 2011). Dalam penelitian ini, sistem pakar yang dibangun merupakan sistem rekomendasi aktivitas untuk pekerja/pegawai yang akan memasuki masa pensiun dengan harapan agar dapat meningkatkan kualitas hidup dari pekerja/pegawai yang akan menjalani memasuki masa pensiun. Sistem ini dalam memberikan rekomendasi aktivitas dilakukan dengan cara mengajukan pertanyaan layaknya seorang pakar.

\subsection{Certainty Factory}

Certainty Factor (CF) digunakan untuk mendukung ketidakpastian pemikiran seorang pakar. Seorang pakar biasanya menganalisis informasi yang ada dengan ungkapan ketidakpastian, dan menggunakan certainty factor guna menggambarkan tingkat keyakinan pakar terhadap masalah yang sedang dihadapi. Certainty factor menggunakan nilai untuk mendukung tingkat keyakinan seorang pakar terhadap suatu data (Silaban, 2020).

Penggunaan rumus certainty factory dalam aturan IF THEN menggunakan rumus:

$\mathrm{CF}(\mathrm{H}, \mathrm{e})=\mathrm{CF}(\mathrm{E}, \mathrm{e})^{*} \mathrm{CF}(\mathrm{H}, \mathrm{E})$

Jika semua evidence dalam antecedent diketahui dengan pasti maka rumus yang digunakan menjadi:

$\mathrm{CF}(\mathrm{H}, \mathrm{e})=\mathrm{CF}(\mathrm{H}, \mathrm{E})$.

Dan jika terdapat kaidah produksi yang menghasilkan hipotesis yang sama maka perhitungan certainty factor menjadi:

$C F_{\text {combine } 1}\left(C F_{\text {aturan } 1}, C F_{\text {aturan } 2}\right)=C F_{\text {aturan } 1}+$ $C F_{\text {aturan } 2} *\left(1-C F_{\text {aturan } 1}\right)=$

$C F_{\text {old } 1} C F_{\text {combine } 2}\left(C F_{\text {old } 1}, C F_{\text {aturan } 3}\right)=C F_{\text {old } 1}+$

$C F_{\text {aturan } 3} *\left(1-C F_{\text {old } 1}\right)=C F_{\text {old } 2}$

$C F_{\text {combine } 3}\left(C F_{\text {old } 2}, C F_{\text {aturan } 4}\right)=C F_{\text {old } 2}+$

$C F_{\text {aturan } 4} *\left(1-C F_{\text {old } 2}\right)=C F_{\text {old } 3}$

Keterangan: $C F_{\text {old }}$ terakhir merupakan nilai $\mathrm{CF}$ untuk rekomendasi aktivitas pensiun, berdasarkan hasil perhitungan menggunakan rumus $\mathrm{CF}$ di atas.

\subsection{Akusisi Pengetahuan Dalam Basis Pengetahuan}

Penelitian ini mengumpulkan pengetahuan yang didapat dari wawancara terhadap pakar dan juga referensi seperti buku, dan jurnal penelitianpenelitian sebelumnya. Kegiatan wawancara dilakukan untuk mendapatkan pengetahuan dan informasi mengenai faktor yang pengaruh terkait rekomendasi aktivitas pensiun.

\subsection{Representasi Pengetahuan Dalam Basis Pengetahuan}

Kumpulan pengetahuan direpresentasikan dalam bentuk kode, kemudian dilakukan penginputan ke dalam sebuah basis pengetahuan. Pengkodean disajikan berupa tabel yang di dapat dari hasil wawancara terhadap pakar pada tahap sebelumnya. Ada 42 faktor yang digunakan untuk menentukan rekomendasi aktivitas dan 10 rekomendasi aktivitas. Dapat dilihat pada Tabel 1-12.

Tabel 1. Pengkodean Faktor Psikis Gangguan Mental

\begin{tabular}{lll}
\hline No & Kode Faktor & Faktor \\
\hline 1 & FA001 & Cemas \\
2 & FA002 & Depresi \\
3 & FA003 & Normal \\
4 & FA004 & Gangguan Penyesuaian \\
\hline
\end{tabular}

Tabel 2. Pengkodean Faktor Psikis Spiritual

\begin{tabular}{lll}
\hline No & Kode Faktor & Faktor \\
\hline 1 & FA005 & Religius \\
2 & FA006 & Non Religius \\
\hline & & \\
& Tabel 3. Pengkodean Faktor Psikis Tipe Kepribadian \\
\hline No & Kode Faktor & Faktor \\
\hline 1 & FA007 & Tipe Konstruktif \\
2 & FA008 & Tipe Mandiri \\
3 & FA009 & Tipe Tergantung \\
4 & FA010 & Tipe Bermusuhan \\
5 & FA011 & Tipe Kritik Diri \\
\hline
\end{tabular}

Tabel 4. Pengkodean Faktor Media 10 Penyakit Tertinggi

\begin{tabular}{lll}
\hline No & $\begin{array}{l}\text { Kode } \\
\text { Faktor }\end{array}$ & Faktor \\
\hline 1 & FA012 & Hipertensi \\
2 & FA013 & Artritis \\
3 & FA014 & Stroke \\
4 & FA015 & Penyakit Paru Obstruksi \\
& & Kronik \\
5 & FA016 & DM \\
6 & FA017 & Kanker \\
7 & FA018 & Penyakit Jantung Koroner \\
8 & FA019 & Batu Ginjal \\
9 & FA020 & Gagal Jantung \\
10 & FA021 & Gagal Ginjal \\
\hline
\end{tabular}

Tabel 5. Pengkodean Faktor Medis Disabilitas

\begin{tabular}{lll}
\hline No & $\begin{array}{l}\text { Kode } \\
\text { Faktor }\end{array}$ & Faktor \\
\hline 1 & FA022 & Mendengar \\
2 & FA023 & Melihat \\
3 & FA024 & Berjalan \\
4 & FA025 & Mengingat/Berkomunikasi/ \\
& & Berkonsentrasi \\
5 & FA026 & Mengurus Diri Sendiri \\
\hline
\end{tabular}

Tabel 6. Pengkodean Faktor Ekonomi

\begin{tabular}{lll}
\hline No & Kode Faktor & Faktor \\
\hline 1 & FA027 & Tinggi \\
2 & FA028 & Sedang \\
3 & FA029 & Rendah \\
\hline
\end{tabular}


Tabel 7. Pengkodean Faktor Lingkungan Kerja

\begin{tabular}{lll}
\hline No & Kode Faktor & Faktor \\
\hline 1 & FA030 & Kerjasama \\
2 & FA031 & Tidak Bisa \\
& & Kerjasama \\
\hline
\end{tabular}

Tabel 8. Pengkodean Faktor Lingkungan Masyarakat

\begin{tabular}{lll}
\hline No & Kode Faktor & Faktor \\
\hline 1 & FA032 & Urban \\
2 & FA033 & Rural \\
\hline & & \\
& Tabel 9. Pengkodean Faktor Lingkungan Keluarga \\
\hline No & Kode Faktor & Faktor \\
\hline 1 & FA034 & Harmonis \\
2 & FA035 & Tidak Harmonis \\
\hline
\end{tabular}

Tabel 10. Pengkodean Faktor Pendidikan

\begin{tabular}{lll}
\hline No & Kode Faktor & Faktor \\
\hline 1 & FA036 & SMA \\
2 & FA037 & S1 \\
3 & FA038 & S2 \\
4 & FA039 & S3 \\
\hline
\end{tabular}

Tabel 11. Pengkodean Faktor Jabatan

\begin{tabular}{lll}
\hline No & Kode Faktor & Faktor \\
\hline 1 & FA040 & Pimpinan \\
2 & FA041 & Staf \\
3 & FA042 & Tanpa Jabatan \\
\hline
\end{tabular}

Tabel 12. Pengkodean Rekomendasi Aktivitas

\begin{tabular}{|c|c|c|}
\hline No & $\begin{array}{l}\text { Kode } \\
\text { Rekomendasi }\end{array}$ & Rekomendasi \\
\hline 1 & RK001 & $\begin{array}{l}\text { Melanjutkan hobi yang } \\
\text { tertunda atau lakukan hobi } \\
\text { baru }\end{array}$ \\
\hline 2 & RK002 & Berolahraga \\
\hline 3 & RK003 & $\begin{array}{l}\text { Menjadi pekerja paruh } \\
\text { waktu }\end{array}$ \\
\hline 4 & RK004 & Bisnis atau Investasi \\
\hline 5 & RK005 & Melakukan traveling \\
\hline 6 & RK006 & $\begin{array}{l}\text { Menghabiskan waktu } \\
\text { bersama keluarga }\end{array}$ \\
\hline 7 & RK007 & $\begin{array}{l}\text { Bergabung dalam } \\
\text { organisasi atau kelompok }\end{array}$ \\
\hline 8 & RK008 & Membuka usaha sendiri \\
\hline 9 & RK009 & Memperdalam agama \\
\hline 10 & RK010 & Menjadi sukarelawan \\
\hline
\end{tabular}

\subsection{Basis Pengetahuan Rekomendasi Aktivitas Pensiun}

Basis pengetahuan adalah inti dari program sistem pakar, karena basis pengetahuan ini menjadi bagian dalam representasi pengetahuan dari seorang pakar tersebut (Hayadi \& Rukun, 2016). Basis pengetahuan ini menggunakan penalaran berbasis aturan atau biasa disebut rule-base reasoning yang berbentuk IF-THEN.

Dalam basis pengetahuan ini setelah pengetahuan direpresentasikan dalam bentuk kode kemudian dibuatkan rule/aturan dalam bentuk tabel agar mudah dipahami, diformulasikan dan untuk menyelesaikan masalah yang terjadi pada sistem, fungsi basis pengetahuan sebagai sumber referensi dalam pengambilan sebuah keputusan. Penyusunan basis pengetahuan berdasarkan pada pengolahan data dari referensi studi literatur dan mencocokkan hasil penyusunan basis pengetahuan kepada pakar yang bersangkutan. Terdapat 42 Faktor untuk merekomendasikan 10 aktivitas(Tabel 14). Kaidah produksi atau peraturan yang menilai certainty factor (CF) diberikan oleh seorang pakar. Pemisalan untuk sebuah faktor yang berpotensi memberikan rekomendasi menjadi sukarelawan, terdapat 15 rule sebagai berikut:

Tabel 13. Tabel Sampel Rule

\begin{tabular}{ll}
\hline No & Rule \\
\hline 1 & IF normal AND Religius AND Tipe \\
& konstruktif AND Hipertensi AND Ekonomi \\
& Tinggi AND Bisa Kerjasama AND Urban \\
& AND Harmonis AND S2 AND Pimpinan \\
& THEN Menjadi sukarelawan, $C F_{\text {pakar }}=0,4$
\end{tabular}

2 IF normal AND Religius AND Tipe konstruktif AND Hipertensi AND Ekonomi Tinggi AND Bisa Kerjasama AND Urban AND Harmonis AND S3 AND Pimpinan THEN Menjadi sukarelawan, $C F_{\text {pakar }}=0,4$

3 IF normal AND Religius AND Tipe konstruktif AND Hipertensi AND Ekonomi Tinggi AND Bisa Kerjasama AND Urban AND Harmonis AND S1 AND Pimpinan THEN Menjadi sukarelawan, $C F_{\text {pakar }}=0,4$

4 IF normal AND Religius AND Tipe konstruktif AND Hipertensi AND Ekonomi Tinggi AND Bisa Kerjasama AND Urban AND Harmonis AND S1 AND Staff THEN Menjadi sukarelawan, $C F_{\text {pakar }}=0,4$

5 IF normal AND Religius AND Tipe konstruktif AND Hipertensi AND Hipertensi AND Ekonomi Sedang AND Bisa Kerjasama AND Urban AND Harmonis AND S2 AND Pimpinan THEN Menjadi sukarelawan, $C F_{\text {pakar }}=0,4$

6 IF normal AND Religius AND Tipe konstruktif AND Hipertensi AND Ekonomi Sedang AND Bisa Kerjasama AND Urban AND Harmonis AND S3 AND Pimpinan THEN Menjadi sukarelawan, $C F_{\text {pakar }}=0,4$

7 IF normal AND Non Religius AND Tipe konstruktif AND Hipertensi AND Ekonomi Sedang AND Bisa Kerjasama AND Urban AND Harmonis AND S1 AND Pimpinan THEN Menjadi sukarelawan, $C F_{\text {pakar }}=0,4$

8 IF normal AND Non Religius AND Tipe konstruktif AND Hipertensi AND Ekonomi Sedang AND Bisa Kerjasama AND Urban AND Harmonis AND S1 AND Staff THEN Menjadi sukarelawan, $C F_{\text {pakar }}=0,4$

9 IF normal AND Religius AND Tipe mandiri AND Hipertensi AND Ekonomi Sedang 


\begin{tabular}{ll}
\hline No & Rule \\
\hline & AND Bisa Kerjasama AND Urban AND \\
& Harmonis AND S2 AND Pimpinan THEN \\
Menjadi sukarelawan, $C F_{\text {pakar }}=0,4$ \\
10 & IF normal AND Religius AND Tipe mandiri \\
& AND Hipertensi AND Ekonomi Sedang \\
AND Bisa Kerjasama AND Urban AND \\
Harmonis AND S3 AND Pimpinan THEN \\
Menjadi sukarelawan, $C F_{\text {pakar }}=0,4$ \\
IF normal AND Religius AND Tipe \\
konstruktif AND Ekonomi Tinggi AND Bisa \\
Kerjasama AND Urban AND Harmonis \\
AND S2 AND Pimpinan THEN Menjadi \\
sukarelawan, $C F_{\text {pakar }}=0,6$ \\
IF normal AND Religius AND Tipe \\
konstruktif AND Ekonomi Tinggi AND Bisa \\
Kerjasama AND Urban AND Harmonis \\
AND S3 AND Pimpinan THEN Menjadi \\
sukarelawan, $C F_{\text {pakar }}=0,6$ \\
IF normal AND Religius AND Tipe \\
konstruktif AND Ekonomi Tinggi AND Bisa \\
Kerjasama AND Urban AND Harmonis \\
AND S1 AND Pimpinan THEN Menjadi \\
sukarelawan, $C F_{\text {pakar }}=0,6$ \\
IF normal AND Religius AND Tipe \\
konstruktif AND Ekonomi Tinggi AND Bisa \\
Kerjasama AND Urban AND Harmonis \\
AND S1 AND Staff THEN Menjadi \\
sukarelawan, $C F_{\text {pakar }}=0,6$ \\
IF normal AND Non Religius AND Tipe \\
konstruktif AND Ekonomi sedang AND \\
Bisa Kerjasama AND Urban AND Harmonis \\
AND S2 AND Pimpinan THEN Menjadi \\
sukarelawan, $C F_{\text {pakar }}=0,6$ \\
\hline
\end{tabular}

\subsection{Perancangan Perangkat Lunak}

Perancangan perangkat lunak dalam penelitian ini meliputi beberapa aspek seperti:

1. Merancangan Sistem

(Unified Modeling Language) UML merupakan bahasa pemodelan standar yang didalamnya memiliki sintaks dan semantik. UML (Unified Modeling Language) tidak hanya berisi diagram saja, akan tetapi memiliki alur dalam konteksnya (Dewi \& Saefudin, 2018).

Perancangan sistem menggunakam UML (Unified Modeling Language), terdiri dari use case, dan class diagram. Berikut adalah diagram-diagram UML yang digunakan dalam model basis pengetahuan dalam merekomendasikan aktivitas pensiun:

Use Case Diagram adalah salah satu diagram UML yang dapat digunakan untuk menggambarkan fungsionalitas dari suatu sistem (Dewi \& Saefudin, 2018). Gambaran diagram ini menunjukkan pengguna aplikasi dan prilaku aplikasi. Dalam sistem ini, terdapat pengguna sistem yang terdiri dari user umum, dan admin. User umum berperan sebagai pengguna sistem, admin berperan sebagai pengelola sistem.

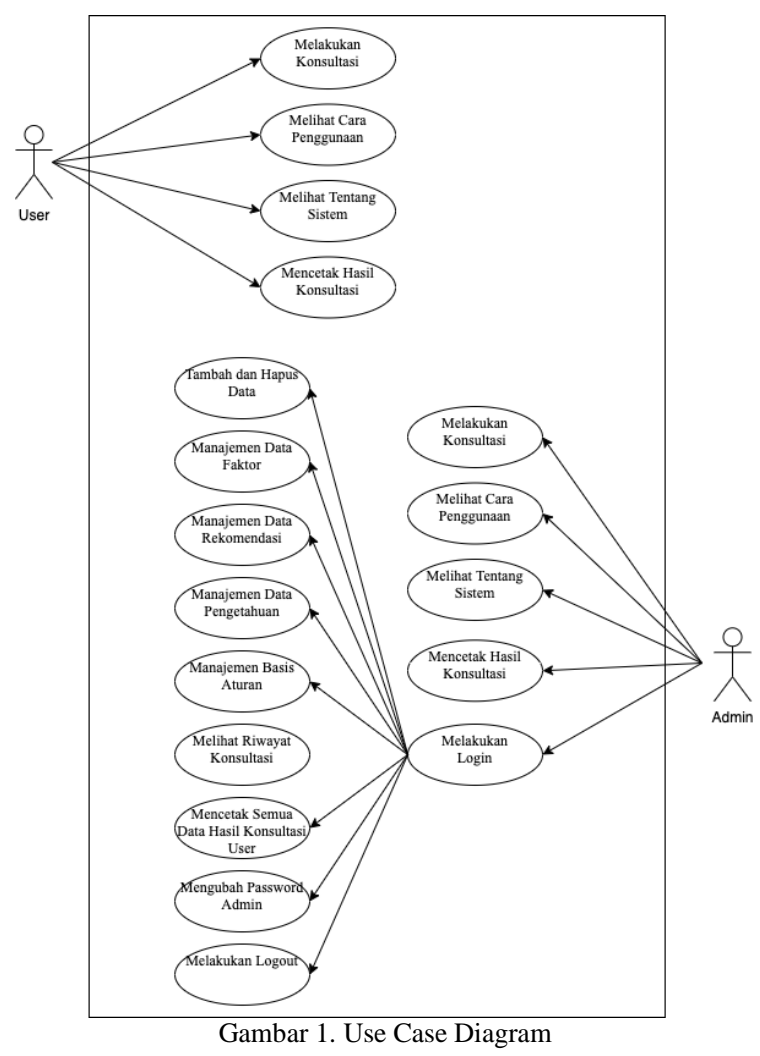

Class diagram merupakan bagian dari jenis diagram statis, yang berfungsi menjelaskan struktur dari sebuah sistem dengan menunjukkan kelas-kelas, interface, atribut-atribut, dan hubungan antar kelas dari struktur sistem tersebut. Class diagram menghasilkan sebuah objek dan bagian inti dari pengembangan dan desain berorientasi objek. Umumnya class diagram suatu sistem menggambarkan bagaimana struktur database yang membangun sistem tersebut.

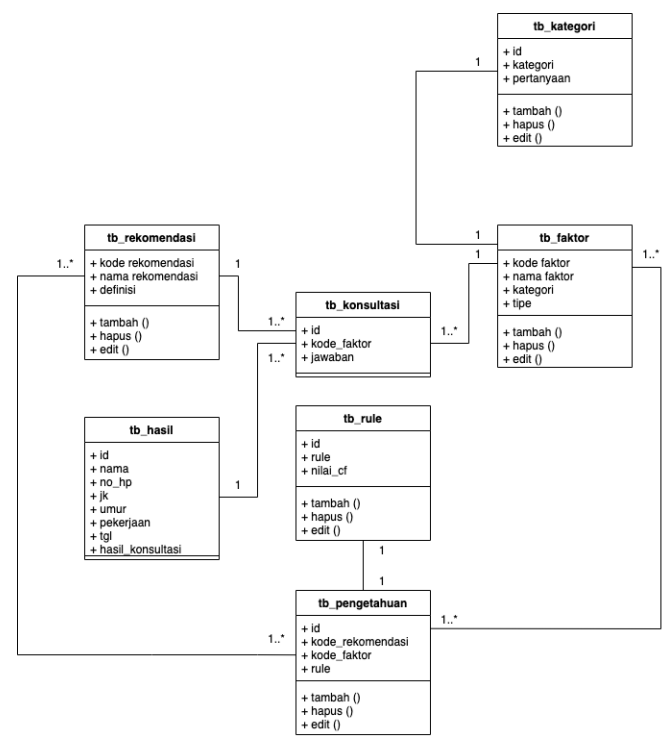

Gambar 2. Class Diagram 
2. Merancang Basis Data

Basis data adalah kumpulan informasi yang tersimpan di dalam komputer secara sistematik sehingga dapat menggunakan program komputer untuk memeriksa infomasi agar dapat memperoleh informasi dari basis data tersebut (Sumadya, Ginardi, \& Akbar, 2016). Basis data tersusun dari entitas serta hubungan antar entitas (Mustasyar \& Akbar, 2017).

Perancangan basis data dalam sistem pakar ini berfungsi sebagai basis pengetahuan yaitu sebagai penyimpanan pengetahuan kepakaran yang diperlukan untuk mengolah data-data, serta menyimpan semua data-data yang diperlukan untuk mendukung rancangan sistem. Terdiri dari 6 Tabel yaitu Tabel faktor,rekomendasi, pengetahuan, rule, konsultasi, dan hasil.

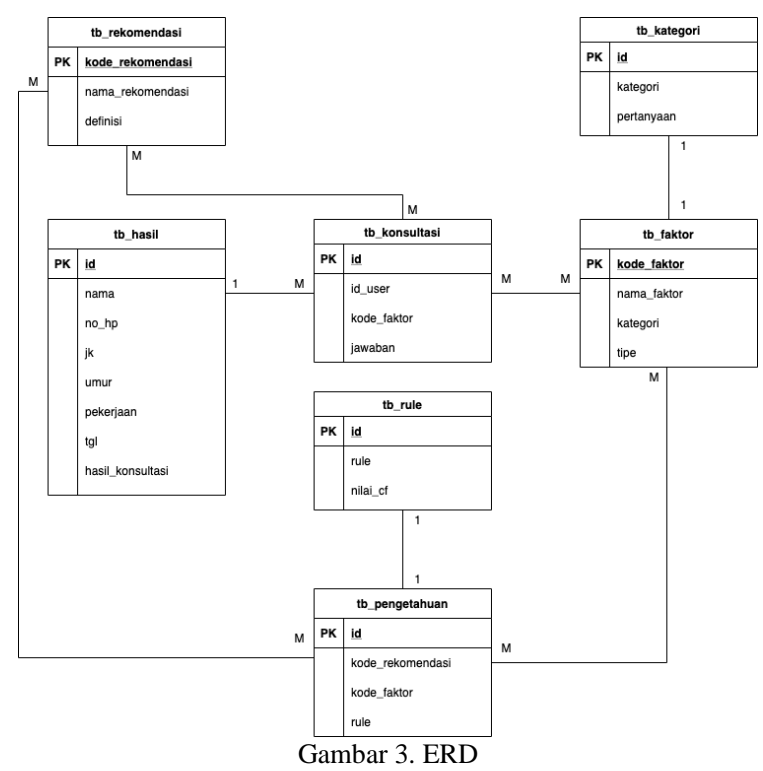

\subsection{Pengujian Perangkat Lunak}

1. Pengujian Fungsional Sistem

Pengujian fungsional sistem pada program ini menggunakan pengujian blackbox, tahapan pengujian dilakukan untuk mengetahui fungsi-fungsi yang terdapat dalam sistem telah berjalan sesuai tujuan yang telah ditetapkan.

2. Pengujian Validitas Sistem

Pengujian ini dilakukan dengan mencocokkan hasil dari output sistem apakah sesuai dengan output aturan yang telah ditetapkan oleh pakar. Pengujian dilakukan dengan manual.

3. Pengujian User Acceptance Test

Pengujian User Acceptance Test dilakukan dengan memberi penilaian terhadap sistem berupa kuisioner. Tujuannya adalah untuk mengetahui kemudahan dalam pengoperasian sistem, dan aspek manfaat yang diperoleh oleh pengguna sistem. Jumlah responden total 30 orang.

\section{HASIL DAN PEMBAHASAN}

\subsection{Hasil Sistem}

Model sistem berbasis pengetahuan untuk rekomendasi aktivitas pensiun ini dibangun berbasis web dengan menggunakan bahasa pemrograman Hypertext Preprocessor atau yang disingkat PHP dan database menggunakan MySQL. Dalam menentukan rekomendasi aktivitas dengan forward chaining, proses pencarian rekomendasi dilakukan saat faktor yang di inputkan sesuai dengan aturan yang telah di buat pada basis pengetahuan dengan cara sistem akan menelusuri faktor-faktor yang ada di dalam basis pengetahuan pada database. Jika sistem menemukan faktor yang diinputkan pada basis pengetahuan sesuai dengan aturan yang ada pada sistem maka sistem akan menampilkan hasil rekomendasi. Sistem akan memberikan nilai keyakinan pada hasil rekomendasi yang menjadi konklusi berdasarkan nilai certainty factor (CF).

Pada halaman konsultasi terdapat 11 pertanyaan dengan jawaban berupa checkbox. Pengguna cukup memilih salah satu jawaban disetiap pertanyaan dengan mngklik pada checkbox. Proses perhitungan prosentase kepastian rekomendasi dengan menggunakan rumus (2) dikarenakan evidence pada antecedent diketahui dengan pasti. Jika terdapat banyak rule dengan konklusi yang sama maka untuk menentukan certainty factor (CF) selanjutnya digunakan persamaan (3).

Berikut ini sample beberapa rule dengan konklusi yang sama pada data rule basis pengetahuan seperti pada Tabel 13.

IF normal AND Religius AND Tipe konstruktif AND Hipertensi AND Mendengar AND Ekonomi Tinggi AND Bisa Kerjasama AND Urban AND Harmonis AND S1 AND Pimpinan THEN Menjadi sukarelawan, $C F_{\text {pakar }}=0,4$.

Dengan menganggap bahwa :

$E_{1}$ : "Normal"

$E_{2}$ : "Religius"

$E_{3}$ : "Tipe konstruktif"

$E_{4}$ : "Hipertensi"

$E_{5}$ : "Mendengar"

$E_{6}$ : "Ekonomi"

$E_{7}$ : "Bisa Kerjasama"

$E_{8}$ : "Urban"

$E_{9}$ : "Harmonis"

$E_{10}$ : "S1"

$E_{11}$ : "Pimpinan"

$\mathrm{H}$ : "Menjadi sukarelawan"

Nilai certainty factor $(\mathrm{CF})$ hipotesis pada saat evidence bernilai pasti adalah:

$$
\begin{aligned}
\mathrm{CF}(\mathrm{H}, \mathrm{e})= & \mathrm{CF}\left(\mathrm{H}, E_{1} \cap E_{2} \cap E_{3} \cap E_{4} \cap E_{5} \cap E_{6} \cap\right. \\
& \left.E_{7} \cap E_{8} \cap E_{9} \cap E_{10} \cap E_{11}\right) * C F_{\text {rule }} \\
\mathrm{CF}(\mathrm{H}, \mathrm{e})= & * 0,4=0,4 \\
\text { Persentase } & =C F_{\text {Rule } 1} * 100 \% \\
& =0,4 * 100 \% \\
& =40 \%
\end{aligned}
$$


Dikarenakan terdapat banyak rule dengan konklusi yang sama maka untuk menentukan $\mathrm{CF}$ selanjutnya digunakan persamaan $C F_{\text {combine }}$ :

$C F_{\text {combine } 1}\left(C F_{\text {rule } 1}, C F_{\text {rule } 2}\right)=C F_{\text {rule } 1}+C F_{\text {rule } 2} *$ $\left(1-C F_{\text {rule } 1}\right)=C F_{\text {old } 1}$

$=0.4+0.4 *(1-0.4)=0.64$

$C F_{\text {combine } 2}\left(C F_{\text {old } 1}, C F_{\text {rule } 3}\right)=C F_{\text {old } 1}+C F_{\text {rule } 3} *(1$

- $\left.C F_{\text {old } 1}\right)=C F_{\text {old } 2}$

$=0.64+0.4 *(1-0.64)=0.784$

$C F_{\text {combine } 3}\left(C F_{\text {old } 2}, C F_{\text {rule } 4}\right)=C F_{\text {old } 2}+C F_{\text {rule } 4} *(1$

$\left.-C F_{\text {old } 2}\right)=C F_{\text {old } 3}$

$=0.784+0.4 *(1-0.784)=0.8704$

$C F_{\text {combine } 4}\left(C F_{\text {old } 3}, C F_{\text {rule } 5}\right)=C F_{\text {old } 3}+C F_{\text {rule } 5} *(1$

$\left.-C F_{\text {old } 3}\right)=C F_{\text {old } 4}$

$=0.8704+0.4 *(1-0.8704)=0.92224$

$C F_{\text {combine } 5}\left(C F_{\text {old } 4}, C F_{\text {rule } 6}\right)=C F_{\text {old } 4}+C F_{\text {rule } 6} *(1$

- $\left.C F_{\text {old } 4}\right)=C F_{\text {old } 5}$

$=0.92224+0.4 *(1-0.92224)=0.953344$

$C F_{\text {combine } 6}\left(C F_{\text {old } 5}, C F_{\text {rule } 7}\right)=C F_{\text {old } 5}+C F_{\text {rule } 7} *(1$

$\left.-C F_{\text {old } 5}\right)=C F_{\text {old } 6}$

$=0.953344+0.4 *(1-0.953344)=0.9720064$

$C F_{\text {combine } 7}\left(C F_{\text {old } 6}, C F_{\text {rule } 8}\right)=C F_{\text {old } 6}+C F_{\text {rule } 8} *(1$

- $\left.C F_{\text {old } 6}\right)=C F_{\text {old } 7}$

$=0.9720064+0.4 *(1-0.9720064)=0.98320384$

$C F_{\text {combine } 8}\left(C F_{\text {old } 7}, C F_{\text {rule } 9}\right)=C F_{\text {old } 7}+C F_{\text {rule } 9} *(1$

- $\left.C F_{\text {old } 7}\right)=C F_{\text {old } 8}$

$=0.98320384+0.4 *(1-0.98320384)=0.9899223$

$C F_{\text {combine } 9}\left(C F_{\text {old } 8}, C F_{\text {rule } 10}\right)=C F_{\text {old } 8}+C F_{\text {rule } 10} *$

$\left(1-C F_{\text {old } 8}\right)=C F_{\text {old } 9}$

$=0.9899223+0.4 *(1-0.9899223)=0.99395338$

$C F_{\text {combine } 10}\left(C F_{\text {old } 9}, C F_{\text {rule } 11}\right)=C F_{\text {old } 9}+C F_{\text {rule } 11} *$

$\left(1-C F_{\text {old } 9}\right)=C F_{\text {old } 10}$

$=0.99395338+0.6 *(1-0.99395338)=$

0.99758135

$C F_{\text {combine } 11}\left(C F_{\text {old } 10}, C F_{\text {rule } 12}\right)=C F_{\text {old } 10}+$

$C F_{\text {rule } 12} *\left(1-C F_{\text {old } 10}\right)=C F_{\text {old } 11}$

$=0.99758135+0.6 *(1-0.99758135)=$

0.99903254

$C F_{\text {combine } 12}\left(C F_{\text {old } 11}, C F_{\text {rule } 13}\right)=C F_{\text {old } 11}+$

$C F_{\text {rule } 13} *\left(1-C F_{\text {old } 11}\right)=C F_{\text {old } 12}$

$=0.99903254+0.6 *(1-0.99903254)=$

0.99961302

$C F_{\text {combine } 13}\left(C F_{\text {old } 12}, C F_{\text {rule } 14}\right)=C F_{\text {old } 12}+$

$C F_{\text {rule } 14} *\left(1-C F_{\text {old } 12}\right)=C F_{\text {old } 13}$

$=0.99961302+0.6 *(1-0.99961302)=$

0.99984521

$C F_{\text {combine } 14}\left(C F_{\text {old } 13}, C F_{\text {rule } 15}\right)=C F_{\text {old } 13}+$

$C F_{\text {rule } 15} *\left(1-C F_{\text {old } 13}\right)=C F_{\text {old } 14}$

$=0.99984521+0.6 *(1-0.99984521)=$

0,999938083

Dari perhitungan certainty factor didapatkan hasil untuk rekomendasi aktivitas menjadi sukarelawan yang diberikan dengan tingkat keyakinan sebesar 99,99380826\%.

Ketika terdapat rekomendasi berbeda dengan rule yang sama pada masing-masing rule, sistem akan menampilkan semua rekomendasi tersebut dengan mengurutkan berdasarkan nilai $\mathrm{CF}$ tertinggi untuk mendapatkan hasil dengan rekomendasi dengan tingkat keyakinan yang tinggi.

\subsection{Implementasi Sistem}

Saat pertama kali sistem dibuka halaman yang pertama kali muncul adalah halaman utama. Pada halaman ini user dapat langsung melakukan konsultasi.

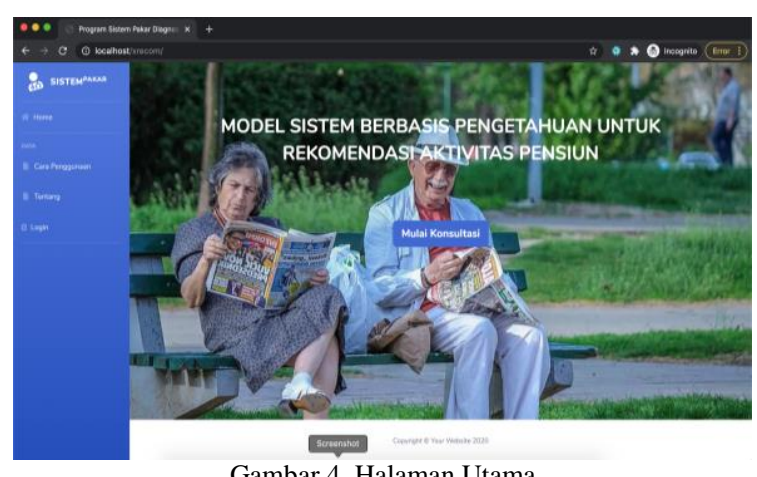

Untuk memulai konsultasi user harus mengklik tombol mulai konsultasi yang ada pada halaman utama seperti pada Gambar 5.

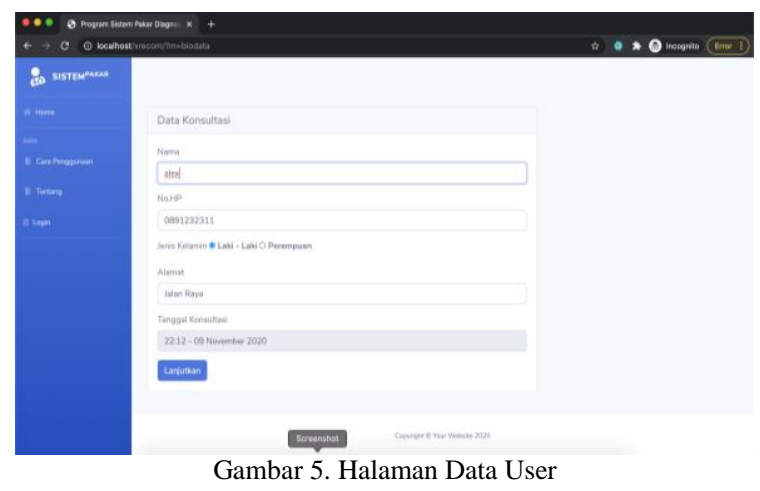

Halaman data user digunakan untuk mengisi data user sebelum melakukan konsultasi. User diminta untuk mengisi data nama,noHP,jenis kelamin, alamat.
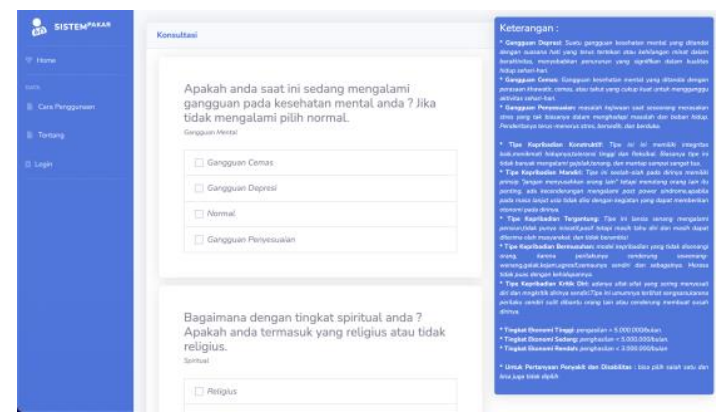

Gambar 6. Halaman Pertanyaan

Setelah melakukan pengisian data, user akan dihadapkan dengan halaman pertanyaan, user diminta untuk menjawab pertanyaan yang ada di halaman pertanyaan dengan cara memilih jawaban pada checkbox dengan cara mengklik pada checkbox. 

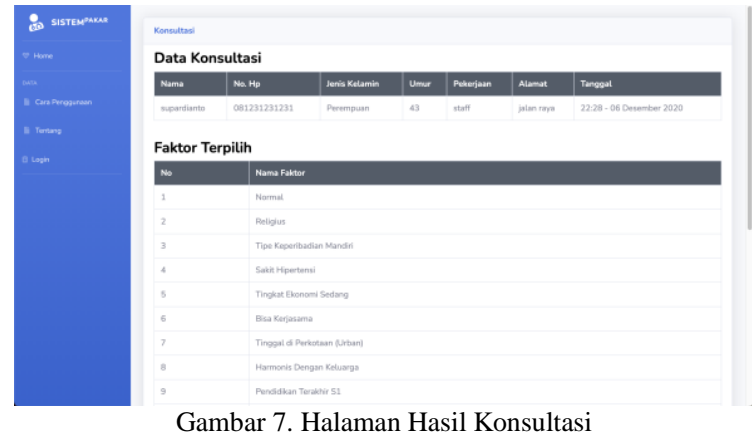

Ketika user selesai menjawab pertanyaan dari sistem, user akan di arahkan ke halaman hasil konsultasi dimana sistem akan memberikan rekomendasi berdasarkan hasil perhitungan certainty factor dengan tingkat keyakinan yang tinggi.

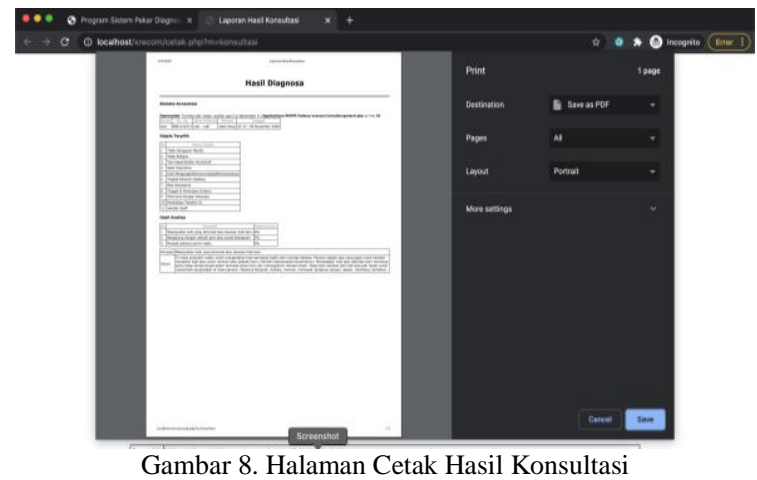

User dapat mencetak hasil konsultasi dengan cara mengklik pada tombol cetak di halaman hasil konsultasi.

\subsection{Pengujian Sistem}

Pengujian model sistem berbasis pengetahuan untuk rekomendasi aktivitas pensiun sementara baru dilakukan dengan uji fungsional, uji validitas, dan uji User Acceptance Test (UAT).

Pengujian fungsional menggunakan blackbox test bertujuan untuk mengetahui fungsi pada sistem yang sudah dibangun dapat berjalan dengan baik atau tidak. Berdasarkan hasil pengujian fungsi yang dilakukan pada sistem, sistem tidak terdapat kendala dengan arti fungsi yang ada di sistem dapat berjalan sesuai dengan yang diharapkan.

Pengujian validitas bertujuan untuk mengetahui hasil analisa dari sistem sesuai dengan hasil analisa dari pakar. Berdasarkan hasil dari pengujian sistem sudah dapat memberikan rekomendasi berdasarkan forward chaining dan nilai certainty factor.

Pengujian User Acceptance Test (UAT) bertujuan untuk mengetahui tanggapan responden (user) terhadap sistem untuk rekomendasi aktivitas pensiun berbasis website, pengujian dilakukan dengan memberikan link google form yang berisikan 6 pertanyaan ke 30 orang responden (user) dimana jawaban dari pertanyaan tersebut terdiri dari nilai yang memiliki tingkatan yang dapat dipilih seperti pada Tabel 14.

Tahapan pengujian User Acceptance Test (UAT) dilakukan dengan beberapa tahapan sebagai berikut:

1. User diminta untuk membuka website rekomendasi aktivitas pensiun terlebih dahulu.

2. User diminta untuk menguji coba sistem dengan memulai konsultasi pada sistem.

3. Setelah user mengetahui hasil konsultasi, kemudian user diberikan link google form yang berisikan kuesioner dan diminta untuk mengisi kuesioner tersebut yang bertujuan untuk mengetahui respon terhadap sistem setelah user melakukan uji coba terhadap sistem.

Tabel 14. Data Jawaban Kuesioner

\begin{tabular}{|c|c|c|c|c|c|c|}
\hline \multirow{2}{*}{ No } & \multirow{2}{*}{ Pertanyaan } & \multicolumn{5}{|c|}{ Jawaban } \\
\hline & & 5 & 4 & 3 & 2 & 1 \\
\hline 1 & $\begin{array}{l}\text { Sistem yang dibangun ini } \\
\text { mudah dipelajari. }\end{array}$ & 6 & 19 & 5 & 0 & 0 \\
\hline 2 & $\begin{array}{l}\text { Sistem yang dibangun ini } \\
\text { mudah digunakan. }\end{array}$ & 9 & 16 & 5 & 0 & 0 \\
\hline 3 & $\begin{array}{l}\text { Sistem ini membantu dalam } \\
\text { memberikan rekomendasi } \\
\text { aktivitas untuk persiapan } \\
\text { pensiun. }\end{array}$ & 12 & 17 & 1 & 0 & 0 \\
\hline 4 & $\begin{array}{l}\text { Sistem yang dibangun dapat } \\
\text { memberikan dampak positif. }\end{array}$ & 4 & 17 & 9 & 0 & 0 \\
\hline 5 & $\begin{array}{l}\text { Hasil konsultasi yang } \\
\text { diberikan sistem sesuai } \\
\text { dengan yang diharapkan. }\end{array}$ & 0 & 11 & 19 & 0 & 0 \\
\hline 6 & $\begin{array}{l}\text { Tampilan antarmuka sistem } \\
\text { sangat menarik dan juga } \\
\text { informasi yang diberikan } \\
\text { sangat jelas. }\end{array}$ & 11 & 17 & 2 & 0 & 0 \\
\hline
\end{tabular}

Pada Tabel 15 data diolah dengan cara mengalikan setiap nilai pada jawaban dengan bobot yang ada di tabel bobot nilai jawaban yang sudah ditentukan, kemudian semua nilai akan dijumlahkan untuk mengetahui jumlah nilai keseluruhan setiap pertanyaan.

Tabel 15. Pengolahan Data Jawaban Kuesioner

\begin{tabular}{|c|c|c|c|c|c|c|c|}
\hline \multirow{2}{*}{ No } & \multirow{2}{*}{ Pertanyaan } & \multicolumn{5}{|c|}{ Nilai } & \multirow[t]{2}{*}{ Jumlah } \\
\hline & & 5 & 4 & 3 & 2 & 1 & \\
\hline 1 & $\begin{array}{l}\text { Sistem yang dibangun } \\
\text { ini mudah dipelajari. }\end{array}$ & 30 & 76 & 15 & 0 & 0 & 121 \\
\hline 2 & $\begin{array}{l}\text { Sistem yang dibangun } \\
\text { ini mudah digunakan. }\end{array}$ & 45 & 64 & 15 & 0 & 0 & 124 \\
\hline 3 & $\begin{array}{l}\text { Sistem ini membantu } \\
\text { dalam memberikan } \\
\text { rekomendasi aktivitas } \\
\text { untuk persiapan pensiun. }\end{array}$ & 60 & 68 & 3 & 0 & 0 & 131 \\
\hline 4 & $\begin{array}{l}\text { Sistem yang dibangun } \\
\text { dapat memberikan } \\
\text { dampak positif. }\end{array}$ & 20 & 68 & 27 & 0 & 0 & 115 \\
\hline 5 & $\begin{array}{l}\text { Hasil konsultasi yang } \\
\text { diberikan sistem sesuai } \\
\text { dengan yang diharapkan. }\end{array}$ & 0 & 44 & 57 & 0 & 0 & 101 \\
\hline 6 & $\begin{array}{l}\text { Tampilan antarmuka } \\
\text { sistem sangat menarik } \\
\text { dan juga informasi yang } \\
\text { diberikan sangat jelas. }\end{array}$ & 55 & 68 & 6 & 0 & 0 & 129 \\
\hline
\end{tabular}

Untuk mengolah data pada Tabel 15. digunakan rumus setiap jumlah nilai dari setiap pertanyaan 
akan dibagi dengan jumlah keseluruhan total responden untuk mendapatkan nilai rata-rata dari total nilai responden setiap pertanyaan, kemudian dari nilai rata-rata yang didapat dari setiap pertanyaan akan dibagi dengan jumlah total bobot dan di kalikan dengan $100 \%$ untuk mendapatkan persentase untuk setiap pertanyaan. Untuk lebih jelasnya berikut perhitungan untuk setiap pertanyaan

1. Pertanyaan pertama

Total nilai dari 30 responden pada pertanyaan pertama adalah 121 . Kemudian untuk mencari nilai rata-ratanya adalah $121 / 30=4,03$. Untuk mencari persentase nilai pada pertanyaan kesatu adalah $4,03 / 5 * 100=80,6 \%$. Jadi untuk persentase nilai pada pertanyaan kesatu adalah $80,6 \%$

2. Pertanyaan kedua

Total nilai dari 30 responden pada pertanyaan kedua adalah 124. Kemudian untuk mencari nilai rata-ratanya adalah $124 / 30=4,13$. Untuk mencari persentase nilai pada pertanyaan kedua adalah $4,13 / 5 * 100=82,6 \%$. Jadi untuk persentase nilai pada pertanyaan kedua adalah $82,6 \%$.

3. Pertanyaan ketiga

Total nilai dari 30 responden pada pertanyaan ketiga adalah 131. Kemudian untuk mencari nilai rata-ratanya adalah $131 / 30=4,37$. Untuk mencari persentase nilai pada pertanyaan ketiga adalah 4,37/5 * $100=87,4 \%$. Jadi untuk persentase nilai pada pertanyaan ketiga adalah $87,4 \%$.

4. Pertanyaan keempat

Total nilai dari 30 responden pada pertanyaan keempat adalah 115. Kemudian untuk mencari nilai rata-ratanya adalah $115 / 30=3,83$. Untuk mencari persentase nilai pada pertanyaan keempat adalah $3,83 / 5 * 100=76,6 \%$. Jadi untuk persentase nilai pada pertanyaan keempat adalah $76,6 \%$.

5. Pertanyaan kelima

Total nilai dari 30 responden pada pertanyaan kelima adalah 101. Kemudian untuk mencari nilai rata-ratanya adalah $101 / 30=3,36$. Untuk mencari persentase nilai pada pertanyaan kelima adalah $3,36 / 5 * 100=67,2 \%$. Jadi untuk persentase nilai pada pertanyaan kelima adalah $67,2 \%$

\section{Pertanyaan keenam}

Total nilai dari 30 responden pada pertanyaan keenam adalah 129. Kemudian untuk mencari nilai rata-ratanya adalah $129 / 30=4,3$. Untuk mencari persentase nilai pada pertanyaan keenam adalah $4,3 / 5 * 100=86 \%$. Jadi untuk persentase nilai pada pertanyaan keenam adalah $86 \%$.

Persentase rata-rata pertanyaan didapat dari jumlah keseluruhan persentase pertanyaan dibagi dengan total pertanyaan dengan perhitungan sebagai berikut :

$$
\begin{gathered}
(80,6 \%+82,6 \%+87,4 \%+76,6 \%+67,2 \%+ \\
86 \%) / 6=80,06 \%
\end{gathered}
$$

Dari data diatas dapat disimpulkan bahwa model sistem berbasis pengetahuan untuk rekomendasi aktivitas pensiun tersebut dapat membantu dalam memberikan aktivitas untuk persiapan pensiun, tampilan antarmuka sistem yang menarik dan informasi jelas dipahami, sistem mudah digunakan, dan sistem juga mudah untuk dipelajari. Hal tersebut ditunjukkan dengan nilai rata-rata persentase sebesar $80,06 \%$ yang didapat dari penilaian terhadap 30 responden yang telah menjawab kuesioner yang telah di berikan.

\section{KESIMPULAN}

Berdasarkan hasil penelitian mengenai model sistem berbasis pengetahuan untuk rekomendasi aktivitas pensiun, dapat diambil kesimpulan:

1. Sistem ini dapat memberikan rekomendasi aktivitas pensiun berdasarkan faktor-faktor yang dipilih pengguna/user ketika pengguna/user menjawab semua pertanyaan yang diajukan oleh sistem.

2. Metode Forward Chaining yang dikombinasikan dengan Metode Certainty Factor pada sistem yang dibangun dapat memberikan hasil yang sesuai dengan fungsi yang digunakan dalam memberikan rekomendasi berdasarkan pelacakan dari faktor-faktor yang telah terpilih untuk kemudian mencocokan dengan rule yang ada di sistem sehingga memperoleh suatu konklusi dan memberikan tingkat keyakinan pada konklusi berdasarkan perhitungan pada rule nilai certainty factor.

3. Dari hasil pengujian blackbox didapat bahwa semua fungsi sistem sudah memenuhi yang diharapkan dengan hasil sukses/bebas dari kesalahan.

4. Dari pengujian User Acceptance Test yang dilakukan terhadap 30 responden dapat disimpulkan bahwa sistem ini membantu dalam memberikan rekomendasi aktivitas untuk persiapan pensiun dengan persentase $87,4 \%$, tampilan antarmuka sistem sangat menarik dan juga informasi yang diberikan sangat jelas dengan persentase $86 \%$, sistem yang dibangun ini mudah digunakan dengan persentase $82,6 \%$ dan sistem yang dibangun ini mudah dipelajari dengan persentase $80,6 \%$. Hal tersebut ditunjukkan dengan nilai rata-rata persentase sebesar 80,06 \% akan tetapi pada hasil konsultasi yang diberikan sistem sesuai dengan yang diharapkan memberikan persentase sebesar $67,2 \%$ karena pada keterangan rekomendasi yang diberikan belum ditampilkan dengan lengkap. 


\section{UCAPAN TERIMA KASIH}

Terima kasih untuk para promotor dan keluarga.

\author{
Teknik ITS, 5(2), 2-5. \\ https://doi.org/10.12962/j23373539.v5i2.1877
}

\section{DAFTAR PUSTAKA}

ROSNELLY, R. 2011. Sistem Pakar Konsep dan Teori. Yogyakarta: Andi.

DARMOJO, B., \& MARTONO, H. 2015. Buku Ajar Boedhi-Darmojo Geriatri (Ilmu Kesehatan Usia Lanjut) (5 ed.). Jakarta: Badan Penerbit FKUI.

SUTOJO, T., MULYANTO, E., \& SUHARTONO, V. 2011. Kecerdasan buatan. Yogyakarta: Andi Offset.

PRATIWI, H. 2019. Buku Ajar: Sistem Pakar. Kuningan: Goresan Pena.

HAYADI, B. H., \& RUKUN, K. 2016. What is Expert System. Yogyakarta: Deepublish.

DEWI, M., \& SAEFUDIN, M. 2018. Rancang Bangun Sistem Pakar Identifikasi Tentang Penyakit Ginjal Dengan Mengunakan Metode Forward Chaining, 17(September).

KADARISMAN, M. 2011. Menghadapi pensiun dan kesejahteraan psikologis pegawai negeri sipil. Jurnal Kebijakan Dan Manajemen, 5(2), 4562. Retrieved from https://jurnal.bkn.go.id/index.php/asn/article/vi ew/111

MUSTASYAR, D. I., \& AKBAR, R. J. 2017. Rancang Bangun Aplikasi Sistem Basis Data Online Judge (SBDOJ) untuk Proses Pembelajaran Mata Kuliah Sistem Basis Data di Departemen Teknik Informatika ITS. Jurnal Teknik ITS, 6(2), 2-5. https://doi.org/10.12962/j23373539.v6i2.2399 9

PAIDI. 2013. Strategi persiapan masa pensiun bagi para karyawan. WIDYA Ekonomika, 1(1), 1217.

RAHMAN, F. 2017. Perancangan Aplikasi Sistem Pakar Dengan Menggunakan Metode Certainty Factor Untuk Menentukan Jenis Gangguan Disleksia Berbasis Web. Jurnal Inkofar, 1(1), 12-17. https://doi.org/10.46846/jurnalinkofar.v1i1.4

SAFITRI, B. R. 2013. Kesiapan Menghadapi Masa Pensiun Ditinjau Dari Peran Genderkaryawan. Jurnal Ilmiah Psikologi Terapan, 01, 191204.

https://doi.org/https://doi.org/10.22219/jipt.v1i 2.1577

SILABAN, C. 2020. Penerapan Metode Certainty Factor Dalam Mendiagnosa Penyakit Skizofrenia berbasis Komputer. Jurnal Simetrik, 1(2), 32-36. Retrieved from http://ejurnal.seminarid.com/index.php/jharma/article/view/345

SUMADYA, D. O., GINARDI, H. H., \& AKBAR, R. J. 2016. Perancangan dan Implementasi Basis Data Aplikasi Web Fotokita. Jurnal 